\title{
The weightshift-controlled microlight aeroplane
}

\author{
G B Gratton \\ British Microlight Aircraft Association, The Bullring, Deddington, Banbury, Oxfordshire OX15 0TT, UK
}

\begin{abstract}
Microlight aircraft are increasingly becoming the most popular segment of private aviation. In the United Kingdom the majority (about 2500 of a total fleet of 3500) of these aircraft are of the weightshift class, also known as flexwings or trikes. This paper introduces the main issues involved in the design and operation of this class of aeroplane.
\end{abstract}

Keywords: microlight, ultralight, BCAR Section S, trike, flexwing, weightshift, BMAA

\section{NOTATION}

$\begin{array}{ll}\text { AoA } & \text { angle of attack } \\ C_{\mathrm{L}} & \text { lift coefficient } \\ C_{\mathrm{M}} & \text { pitching moment coefficient } \\ \mathrm{CAS} & \text { calibrated air speed } \\ \mathrm{CG} & \text { centre of gravity (centre of mass) } \\ \mathrm{CP} & \text { centre of pressure } \\ V_{\mathrm{S}} & \text { stall or minimum flying speed } \\ V_{\mathrm{SO}} & \begin{array}{l}\text { calibrated stall or minimum flying speed in the } \\ \text { landing configuration at maximum take-off mass }\end{array} \\ \alpha & \text { angle of attack } \\ \tau_{\mathrm{R}} & \text { roll mode time constant }\end{array}$

\section{INTRODUCTION}

Microlight aircraft are defined [1] as aeroplanes having no more than two seats, $V_{\text {SO }}$ not exceeding 35 knots CAS and a maximum take-off mass of no more than:

(a) $300 \mathrm{~kg}$ for a landplane, single seater, or

(b) $450 \mathrm{~kg}$ for a landplane, two-seater, or

(c) $330 \mathrm{~kg}$ for an amphibian or floatplane, single seater, or

(d) $495 \mathrm{~kg}$ for an amphibian or floatplane, two seater.

There are three control systems used in this class of aircraft: these are three axis controlled (conventional aeroplane controls), weightshift controlled and powered parachutes (the last of these using an enlarged paraglider-style wing).

The weightshift-controlled microlight aeroplane, also referred to in the UK as the 'flexwing' or in the USA as the

The MS was received on 14 November 2000 and was accepted after revision for publication on 8 February 2001. 'trike', is the most numerous type of microlight aircraft with some 2500 such aircraft in the United Kingdom alone, from a large number of manufacturers [2], of which four are currently either building aircraft in the UK or supplying kits or plans.

This class of aircraft is controlled by direct application of pitching or rolling moments to the wing through a control bar, with the mass of the 'trike' unit suspended below the wing providing the necessary reaction. This means that, from the pilot's perspective, the bar is pushed to starboard to roll to port, and forwards to pitch upwards - the opposite sense to that required for a conventional aeroplane. For this reason pilots not initially trained on this class of aircraft are strongly recommended (although not legally required) to complete conversion training [3] and then to pass an alternative control systems test before flying as pilot in command of a weightshift microlight. The conversion training typically takes $10-12$ flying hours.

Nonetheless, the training requirements for qualification as a microlight pilot $[\mathbf{4 , 5}$ ] are comparatively low; the minimum in the UK is $25 \mathrm{~h}$ of flying training, of which at least $10 \mathrm{~h}$ must be supervised solo flight. Although this minimum is rarely achieved (30-35 h being more normal), it indicates the necessity for aircraft to be extremely simple and safe to operate, particularly given that the majority of such aircraft are owner operated, with private owners conducting most of the routine inspection and maintenance tasks. Microlight aircraft are, however, limited to day visual meteorological conditions operations with sight of the surface [6], which reduces the importance of instrumentation as a safety factor.

Certification of this class of aircraft in the UK is to BCAR Section S [7]; although the certification system is not described in this paper, the reader interested in this issue is referred to reference [6]. Similarly, only the UK position is discussed; although technology is universal, the regulatory issues vary greatly between countries [8]. 


\section{MAIN AIRCRAFT COMPONENTS}

Figure 1 shows a typical weightshift microlight aircraft (a Mainair Blade 912). The aircraft comprises two distinct parts, the trike and the wing. While the interaction between them is essential to the characteristics of the aircraft, it is convenient initially to consider them separately.

\subsection{The wing-structure}

The wing structure of a flexwing microlight (see Fig. 2) is complex and somewhat unlike that of a conventional wing. The primary parts of the structure are the leading edgestwo segmented tubes typically $4.5-5.5 \mathrm{~m}$ long, which are

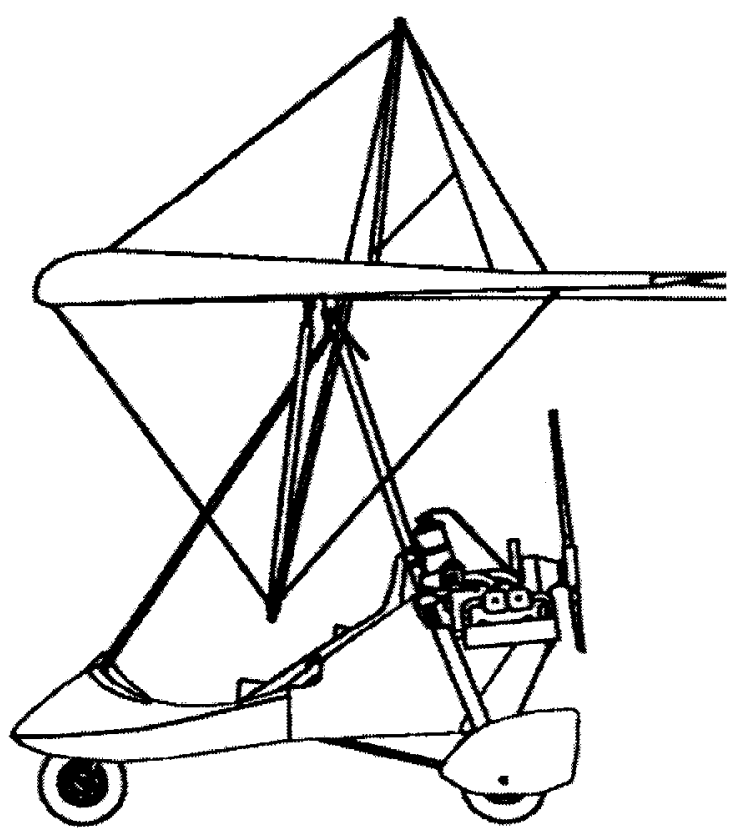

Fig. 1 Mainair Blade joined at the nose to the keel tube which runs the length of the wing and can be seen protruding from the trailing edge in Figs 1 and 5. Stretched over these is the sail manufactured from a high strength synthetic non-porous fabric such as polyester Dacron. The whole structure is put under considerable internal loads during rigging, rigidity and form being ensured by cross-tubes, which are hinged at approximately half-span to the leading edges and hinged to each other above the keel tube. Although they can and must move laterally relative to the keel tube, they are attached to the rear of the keel with a tensioning cable-it is this cable, running the length of the keel, that ensures the form of the wing. The mechanism by which the cross-tubes and keel may move laterally with respect to each other is referred to as a floating keel.

Above the wing is a kingpost, attached through a flexible join above the keel tube. To this are attached the lufflines, landing wires (which are attached to the leading edgecross-tube junction) and usually leading and trailing edge wires to hold it in position. This can be seen in Figs 1 and 2.

Looking at the wing in end view (see Fig. 5), the Aframe, consisting of two uprights and a basebar, is clearly visible. In normal flight, the basebar is not only the primary flight control, providing both roll and pitch control, but also the primary structure, carrying in tension, via the flying wires, much of the wing loads outboard of the cross-tubeleading edge junction. The inboard sections of the leading edge and the A-frame uprights are for the most part in compression.

The position of the basebar is critical to correct control of the aeroplane, the ideal position relative to the pilot being referred to as the 'piano-playing position'. Adjustment of the position of the basebar, when developing a wing, can usually be done by adjusting the front wires and rear wires which run from the ends of the basebar to the nose and rear keel respectively. These wires locate the

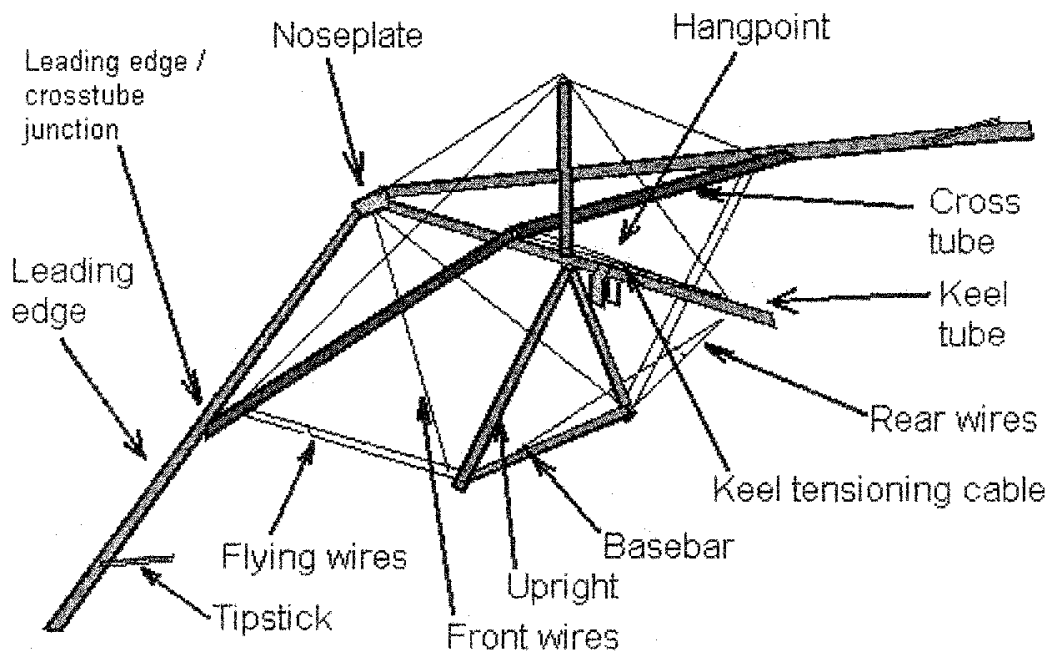

Fig. 2 Wing frame main components (sail and lufflines are omitted for clarity; the lufflines may be seen in Fig. 1, the sail in Fig. 5) 
basebar, while also transmitting pitch control forces to the wing.

It can clearly be seen that the 'wires' in the weightshift wing are extremely critical to the structure of the aircraft. All the structural wires are normally duplicated by parallel wires, perhaps $20-60 \mathrm{~mm}$ away. The exception to this is the lufflines which, although aerodynamically critical, take very little actual load in flight. These are generally simplex and of considerably reduced diameter compared with other structural wires (perhaps $2 \mathrm{~mm}$ diameter, compared with 4-6 $\mathrm{mm}$ diameter for flying wires).

The sail in older designs is usually of a single surface; that is, the upper surface of the aerofoil with no separate lower surface. As the design of flexwings developed during the 1980s, increasingly the forward part of the sail used a lower surface also; modern wings almost universally have both upper and lower aerofoil surfaces throughout. The aerofoil section is maintained by battens, which are formed rods inserted into pockets in the sail and then put under compressive load. A modern wing may have 12-20 battens per side. The shape of these battens is highly critical, and they are subject to regular removal and checking as part of the routine inspection and maintenance of the wing [9].

\subsection{The wing-aerodynamics}

The weightshift wing is a tailless delta which is inherently stable in all three axes; it is normally of 8-10 m wingspan and $2.5-3.5 \mathrm{~m}$ from nose to tip trailing edge. There is no pendular stability, since the trike (the unit hung below the wing, containing crew, undercarriage and powerplant) is suspended at the hangpoint through a joint which is free to rotate in pitch and roll without hindrance.

Longitudinal stability is provided by a combination of washout (twist of the wing between root and tip) and wingsweep [thus producing a downforce at the wingtips, which are significantly behind the centre of gravity (CG)], and reflex (a reversed curvature of the aerofoil section at the inboard trailing edge). At high speeds, the fabric covering of the wing (the sail) will tend to flatten, reducing static stability. This is unacceptable and therefore two devices are incorporated into the wing design to prevent this loss of longitudinal stability. Firstly tipsticks (see Fig. 3), also known as minimum washout rods, are cantilever rods protruding perpendicularly to the leading edge of the

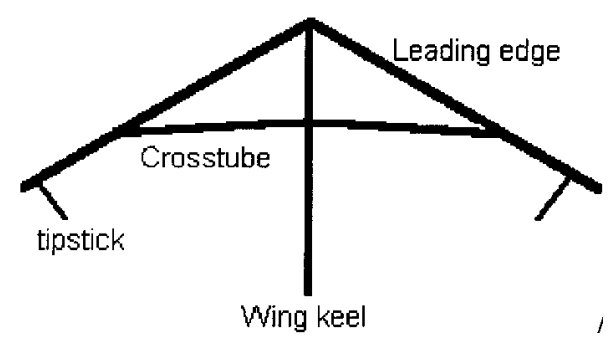

Fig. 3 Wing internal structure (planform) wing beneath (or occasionally within) the sail. By acting as a 'stop' limiting downward aeroelastic movement of the wing fabric near the tips, these prevent the washout at the tips decreasing below a preset value (usually about $3^{\circ}$ ) at low or negative angles of attack. Secondly, lufflines are a series of fixed length lines attached to the kingpost (a rod placed perpendicularly above the centre of the wing) and the trailing edge. These are effective in maintaining reflex at low angles of attack. Although lufflines have always been used in microlight aircraft, their advent in hanggliders in the early 1980s produced a marked reduction in the hang-glider fatal accident rate [10]. The luffing dive was a neutral pitch control point, at which the pilot was denied any pitch control over the wing, usually resulting in an unrecoverable accelerating dive. Figure 4 shows a typical pitching moment versus angle of attack (AoA) curve for a flexwing microlight wing.

On some modern wings (most notably the Pegasus Q2 wing and the Mainair Blade wing) the lufflines also are used to provide a pitch trim mechanism. A tensioning device, controlled from the cockpit, can alter the trim speed through alteration of the amount of reflex. Some hanggliders make use of the washout rods to control pitch trim in flight [11], but the present author is unaware of any microlight aircraft currently making use of this possibility. The 'normal operating region' marked on the figure is limited by the range of AoA attainable within the permitted flight envelope and by the available control authority.

Directional stability is provided in the known fashion of any swept wing. This is usually supplemented by either a keel pocket (a weighted pocket suspended from the wing's structural keel) such as may be seen in Fig. 1, or a fin, protruding above the aft part of the wing. The latter is less common now, but can still be found in the Raven or Sprint wings (Fig. 5). Directional stability of current designs seems to have reached an ideal mid-point between the requirement for adequate directional stability to ensure balanced turns and the need to provide adequate control in turbulence; there have been several recent attempts to fit 'tip-fins' to such wings, which have largely resulted in aircraft virtually uncontrollable in turbulence owing to excessive directional stability.

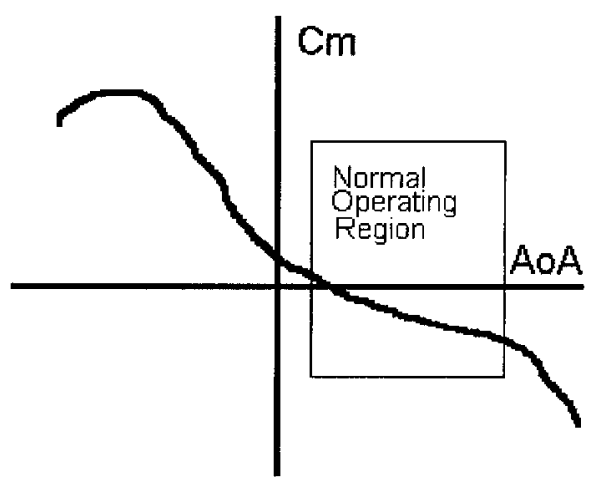

Fig. 4 Typical flexwing pitching moment curve 


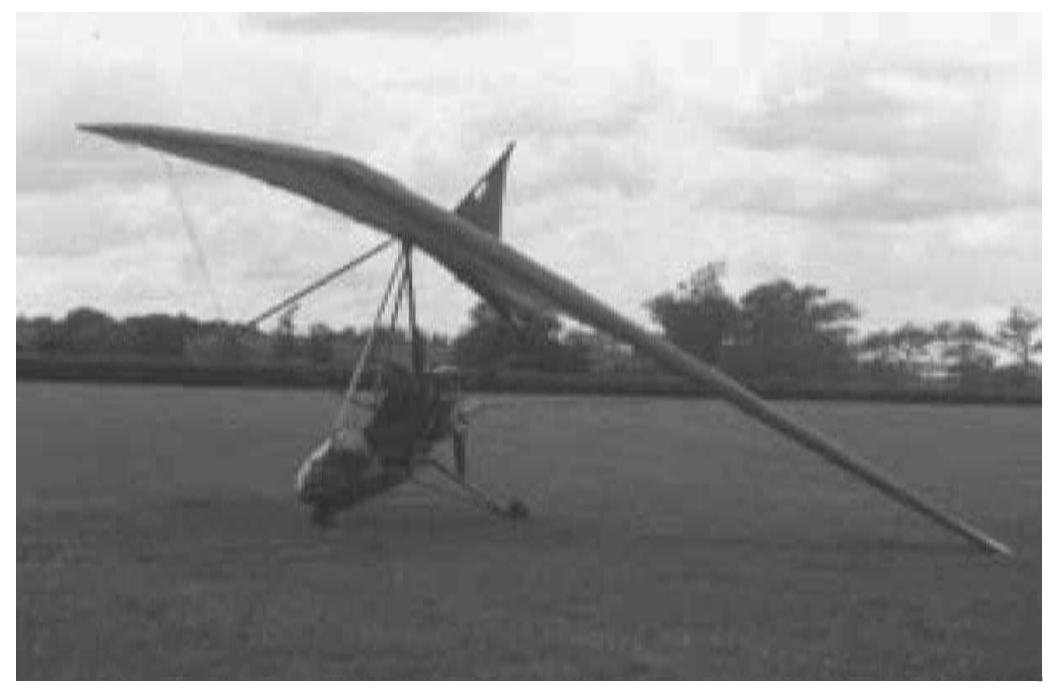

Fig. 5 Raven microlight, showing fin

Lateral stability is provided primarily by a combination of wingsweep and AoA, in the same manner as for any classical delta-winged aeroplane. It is extremely significant that at high AoA the lateral stability becomes extremely high such that roll power becomes weak, while susceptibility of the wing to undemanded rolling due to gusts becomes high. For this reason, pilots must fly at comparatively high speeds (occasionally as high as $2.0 V_{\mathrm{S}}$ ), and thus low AoA during approach or climb-out in particularly turbulent conditions, so that adequate control over the aeroplane can be maintained [12]. None the less, lateral stability can still be unacceptably high, for which reason the wing will employ billow shift. The billow shift mechanism is as follows:

1. Bank is initiated by direct application of a rolling moment through the basebar.

2. The trailing edge of the downgoing wing tends to move upwards, while the trailing edge of the upgoing wing tends to move downwards.

3. This movement is amplified by the lufflines, which are able to slide through a mechanism at the top of the kingpost. In effect, the wing has differential ailerons.

A similar mechanism also occurs at the wingtips, which are outboard of the lufflines, and thus provided with no automatic differential. This is known as leach.

These mechanisms reduce lateral stability and so permit reasonably low control forces and deflections for comparatively high bank angles (most wings should be able to achieve $60^{\circ}$ of bank with perhaps $200 \mathrm{~mm}$ of lateral bar deflection). In a wing with low sail tension, this mechanism can, however, lead to an excessively high value of roll mode time constant $\left(\tau_{\mathrm{R}}\right)$, giving handling problems: because of this it is a certification requirement that such aircraft do not require centring or reversal of roll control when rolling from $60^{\circ}$ to $60^{\circ}$ before passing through wings level $[\mathbf{7}, \mathbf{1 3}]$.

\subsection{The trike-structure}

The most important part of the trike (see Fig. 6) is the monopole; this is the 'vertical' mast extending from the mainwheels to the hangpoint. Engine, wing, seat frame and mainwheels are all attached to this component which is structurally highly critical. Generally, the monopole will consist of two concentric aluminium alloy tubes, with an interference fit between them. While this design should give adequate protection against failure due to fatigue crack propagation around the monopole, most designers also fit a further back-up cable through the centre of the monopole which connects the lower engine mount, or sometimes undercarriage attachment, to the hangpoint.

Horizontally from the base of the monopole runs the trike keel tube to which will be attached the forward part of the seat frame and the nosewheel. From the front of the trike keel tube (also known as the snoot) to the monopole, just below the hangpoint, runs the front strut. Although this

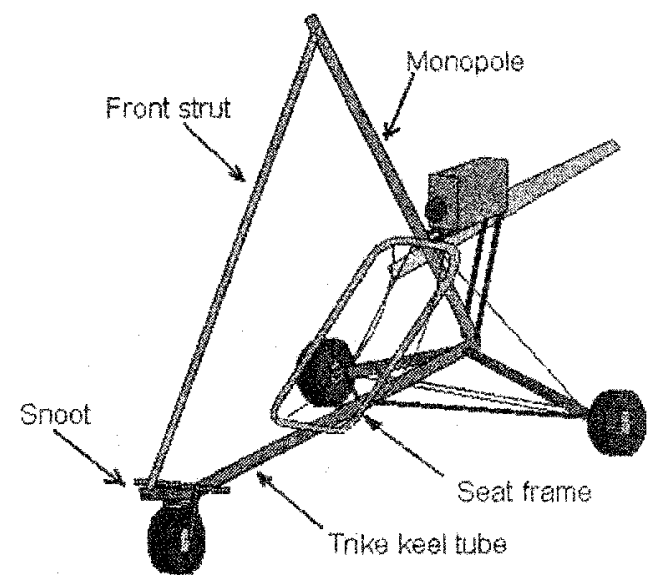

Fig. 6 Simplified trike structure (pod omitted for clarity but may be seen in Fig. 1) 
has the appearance of primary structure, in most flight modes its primary function is of a control stop-preventing the basebar from travelling so far forward that the propeller may strike the rear part of the wing keel. It does, however, serve a function in preventing collapse or inadvertent distortion of the trike frame during either heavy landings or high normal acceleration manoeuvres. The front strut is held in place by a single removable pin at top and bottom; it is essential that it can be easily removed to permit the wing to be removed during derigging. The rigging and derigging operations will be discussed later.

\subsection{The trike-aerodynamics}

To the whole aircraft, the trike does not contribute significant lift, but inevitably a large segment of the drag and all of the thrust through a pusher engine-propeller combination in the $30-75 \mathrm{~kW}(40-100$ h.p.) range. Propellers are usually large (1.5-1.7 m diameter) compared with light aircraft propellers and connected to either a two- or a fourstroke engine through a reduction drive. Two-stroke engines are considerably more common, as are gearbox reduction mechanisms (as compared with belt reduction mechanisms). The reduction mechanism is necessary because of the high (typically 4000-7000 r/min) operating speeds of aircraft two-stroke engines, which would otherwise cause supersonic tip speeds. Reduction ratios vary, although the most common value is $2.58: 1$. Ratios as high as 3.47:1 are used, but 'simple' values such as $2: 1,3: 1$ or $4: 1$ are avoided because of the risk of sympathetic vibrations between engine and propeller, given that most propellers are either two or three bladed. An additional advantage for the designer of a gearbox between propeller and engine is the ability to introduce easily a torsional shock absorber, protecting the engine crankshaft from fatigue-inducing torque fluctuations; this is particularly necessary with modern composite propellers which may possess rotational inertia as high as $5000 \mathrm{~kg} \mathrm{~cm}^{2}$ $\left(0.5 \mathrm{~kg} \mathrm{~m}^{2}\right)$, compared with perhaps $2000 \mathrm{~kg} \mathrm{~cm}^{2}$ $\left(0.2 \mathrm{~kg} \mathrm{~m}^{2}\right)$ for a simple two-bladed wooden propeller.

Aerodynamically the trike often has a significant effect on directional stability [14]. The pod, which protrudes considerably forward of the trike $\mathrm{CG}$, can often have a destabilizing effect in yaw, particularly combined with a powerful engine. For this reason more modern, powerful aircraft tend to use large aerofoil section spats (as may be seen on the Mainair Blade in Fig. 1). Older, less highly powered aircraft such as the Raven in Fig. 5 have less need of this. An interesting demonstration of this problem was the Pegasus XL-Q, an aircraft manufactured in the late 1980s-early 1990s which had a comparatively powerful engine and a large forward pod area. Some examples of this aircraft would display a divergent Dutch roll mode at high speeds, driven partly by poor trike directional stability and partly by poor wing roll damping. The latter was particularly noticeable on aircraft with a multicoloured undersurface, the dyeing process of which had marked effects on the fabric's elastic properties. This is one of the few recorded cases of an aircraft's colour scheme affecting the handling qualities-but any engineer dealing with fabriccovered aircraft should be aware of the risk. The present author's personal experience of flying a 'Rainbow-Q' aircraft was also of a high $\tau_{\mathrm{R}}$ giving less 'crisp' roll control than more soberly coloured wings.

In pitch, the trike mass has the effect of setting the trim speed of the aircraft. The hangpoint (point on the trike keel at which the trike's monopole is attached to the wing) is not at the centre of pressure (CP) and therefore the pitching moment of the trike as suspended from the wing affects the trim speed of the aircraft. In practice it is the position of the hangpoint which affects the trim speed far more than the weight of the trike. In a Medway Raven-X aircraft (Fig. 5), a $70 \mathrm{~mm}$ change in hangpoint position could alter the trim speed in the range 35-60 knots, while a 50 per cent increase in trike suspended weight might increase the trim speed by 3-4 knots. This effect will be discussed in greater depth later in this paper. However, at this point it is important to appreciate that the wing aerodynamics alone, while important, cannot just be regarded separately from the dynamics of the whole, combined system.

Because of the nature of the hangpoint, the trike has no effect on lateral stability other than by increasing or decreasing the load on the wing, and thus the trimmed AoA value.

\section{THE COMBINED AIRCRAFT}

The combined structure of the wing and trike becomes a complete aircraft. They are joined by a single bolt in quadruple shear at the hangpoint, known as the 'hangbolt' or more commonly and colloquially as the 'Jesus bolt', reflecting the available alternatives in the event of a bolt failure-thankfully an almost unknown occurrence. Most designs will also incorporate a back-up strap or cable, attached to the monopole below the hangpoint, which runs loosely around the keel tube. This, in case of a hangbolt failure, is intended to keep the wing and trike together, albeit with control restriction and probably damage to the keel, long enough for a landing to be executed. The present author cannot find any recorded instance of this back-up mechanism ever being tested following an actual hangbolt failure.

So far as the wing and its longitudinal stability is concerned, the $\mathrm{CG}$ is located at the hangpoint. The trike $\mathrm{CG}$, compared with that of a conventional aeroplane, is comparatively irrelevant. It is essential that the trike $\mathrm{CG}$ is such that, when suspended, the mainwheels hang at least $30 \mathrm{~mm}$ below the nosewheel (so as to prevent any risk of a nosewheel-first landing), but beyond that current theory does not consider trike longitudinal $\mathrm{CG}$ to be significant in aircraft stability. However, it is important that the basebar position, which the designer may alter by changing the lengths of front and rear flying wires, is in a roughly central 
position between the pilot's chest and the front strut, thus ensuring adequate longitudinal control in both the nose-up and nose-down senses. Thrust does have a significant effect on the 'hang-angle' of the trike, and thus, although not affecting the trim speed, will alter the ratio of pitch control authority in the nose-up to nose-down directions (i.e. at higher thrust, the trike tends to hang more nose up, and thus the nose-up pitch authority increases since there is greater distance between the basebar and front strut in the trimmed condition).

The trim speed of the aircraft is the airspeed at which the aircraft will tend to fly hands off, variations from which require a continuous force to be applied at the control bar. Apart from the few modern types which use the lufflines to provide a pitch trimmer effect, the majority of weightshift microlights do not have any kind of trimmer and thus the pilot will tend to climb, cruise and descend at constant speed. The value of the trim speed is dictated by four factors:

(a) the form of the $C_{\mathrm{M}^{-}}-\alpha$ curve for the wing;

(b) the form of the $C_{\mathrm{L}}-\alpha$ curve for the wing;

(c) the weight of the trike;

(d) the distance from the hangpoint to the wing CP.

The trim speed will be that speed at which the form of the $C_{\mathrm{M}}-\alpha$ curve shows a pitching moment at the value of $C_{\mathrm{L}}$ necessary for $1 g$ flight at the aircraft weight, equal and opposite to the pitching moment generated by the weight of the trike multiplied by the moment arm between the hangpoint and $\mathrm{CP}$. Both the $C_{\mathrm{M}}-\alpha$ and the $C_{\mathrm{L}}-\alpha$ curves will vary in shape and dimensions as a function of airspeed, owing to the aeroelastic deformation of the wing surface.

The subject of longitudinal static stability of the weightshift aircraft is obviously far more complex than the simplified explanation above, but it is not proposed to discuss the subject, which is still not well understood, further in this paper. However, reference [15] attempts to analyse the problem for hang-gliders, which, although lacking a propulsion device, have similar characteristics.

\section{OPERATIONAL ISSUES}

\subsection{Introduction}

It is the present author's prejudice that it is not possible to understand the design of an aircraft properly without also understanding the operating environment. The microlight industry is particularly fortunate in this respect, in that the majority of company design engineers are also current and experienced pilots in the class of aircraft for which they are responsible. This tends to reduce the risk of significant operational or ergonomic deficiencies reaching even the prototype stage.

In many respects weightshift microlight aircraft are operated in a similar manner to any other privately owned light aeroplane. However, there are significant differences which are important when considering the design of these aircraft.

\subsection{The operating environment}

In the UK, as in many other countries, the law prevents the use of microlight aircraft for hire and reward, other than for flight training or during airworthiness flight testing [16]. For this reason, and the low cost of ownership compared with other classes of aircraft, most aircraft are privately owned by individual pilots or small groups. Because these aircraft are associated with the search for 'cheap' aviation, this usually means that the aircraft are stored in less than ideal facilities (trailers, barns, sheds) and they are operated from what are normally semiprepared or unprepared short $(<500 \mathrm{~m})$ grass airstrips which would probably be impracticable for larger or more conventional aircraft.

Almost universally also, the routine maintenance on these aircraft is conducted by the aircraft owner, who often will have very little formal training or experience in aircraft maintenance, working to a standard [9] or type-specific inspection and maintenance schedule requiring regular inspection of all parts of the aircraft according to time and usage. Adequate safety is then verified by an annual inspection and check flight, carred out by an independent inspector and check pilot; this is required for validation of the permit to fly.

These characteristics demand certain features from a flexwing microlight aircraft: specifically portability, ruggedness and simplicity.

Derigging of a weightshift microlight is in two stages. Firstly the front strut is removed, permitting the monopole to be inclined forwards until the basebar and nose of the wing rest upon the ground. This allows the hangbolt to be removed, and the wing and trike separated. The monopole inclines forward by use of hinged joints at the base of the monopole, and at the centre and each end of the seat frame (see Fig. 7). Some more modern trikes such as the Pegasus Quantum eliminate the seat-folding mechanism by locating the monopole slightly further forward and using a gasfilled compression strut between the monopole and trike keel.

The second stage of derigging is for the link between the keel and cross-tubes to be removed, taking the tension from the system, permitting the leading edges and cross-tubes to be folded parallel to the wing keel and allowing the battens to be removed. The A-frame is also collapsed by removal of the forward flying wire and then removal of the basebar, permitting the pin-jointed A-frame structure to be folded again parallel with the wing keel. This entire process, including folding of the fabric, which remains attached to the wing frame, takes $20-30 \mathrm{~min}$ and leaves the wing in a readily transportable state-a cylinder roughly $5.5 \mathrm{~m} \times$ $0.3 \mathrm{~m}$. The two component parts (wing and trike) of a twoseat aircraft will have empty masses of approximately 50 and $100-130 \mathrm{~kg}$ respectively and are now easily storable or transportable. 


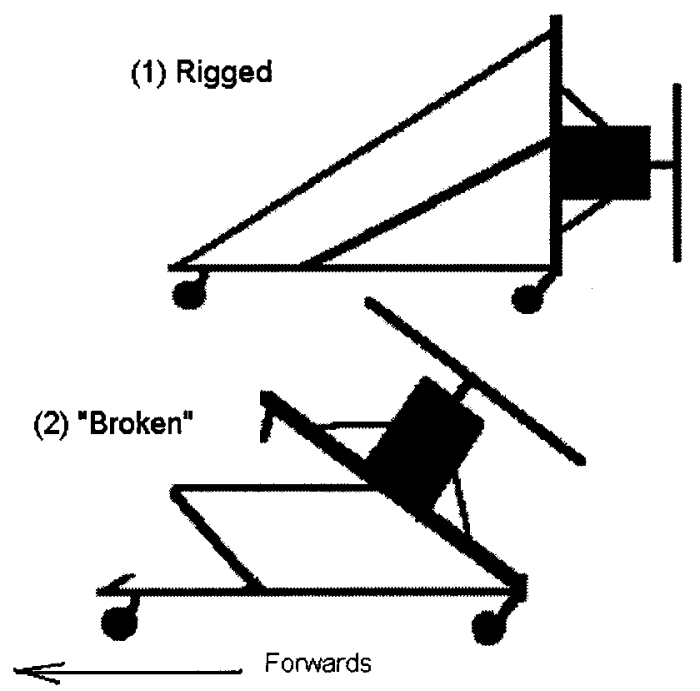

Fig. 7 Conventional trike 'breaking' mechanism

The advantages of this system of routine derigging are routine removal of the wing fabric from exposure to degrading UV radiation, the forced regular inspection of much of the primary aircraft structure by the pilot and the ability to store or transport the aircraft inexpensively. The primary disadvantages are inconvenience to the pilot and wear and tear on the aircraft structure, particularly the sail.

Ruggedness and simplicity in the design of flexwing microlights go together. Virtually all of the structure of the aircraft is constructed from bolted or pin-jointed alloy tube, which is a form of structure that tends to be very flexible under load. Also, because of the simplicity of this, in the event of structural damage, repair is almost invariably by direct replacement, a task which requires very little skill. Virtually all primary structure is duplicated, usually by internal or external sleeving, or internal back-up cables.

Undercarriages, which traditionally are the most dam- age-susceptible parts of a light aircraft, are again manufactured from a pin-jointed tubular structure. Shock absorption is from large tyres, with spring action created by steel cables between the mainwheel hubs (see Fig. 8). This system is aerodynamically very inefficient but is capable of sustaining very large landing shocks, while being inexpensive to construct and largely maintenance free. More modern microlights have used undercarriage shock absorption more similar to that used on a light aircraft, but the system described continues to be the most common and inexpensive design solution.

\section{SUMMARY}

This paper has discussed in outline the main design features and operational consideration in the design of weightshiftcontrolled microlight aeroplanes.

Such aircraft have design features that are significantly different to 'conventional' aeroplanes, and these have been described. Also discussed has been the operating environment of the microlight aircraft which, because of primarily private owner operation, is in many ways more demanding than that to which other classes of light aircraft are routinely exposed.

\section{REFERENCES}

1 Joint Aviation Requirements 1.1, General Definitions, Joint Aviation Authorities.

2 Burr, W. (Ed.) World Directory of Leisure Aviation (Pagefast Limited).

3 Gratton, G. B. Safety for non-microlight pilots. Flight Saf. Bull., Summer 1999, xxxv, 22, 31-33.

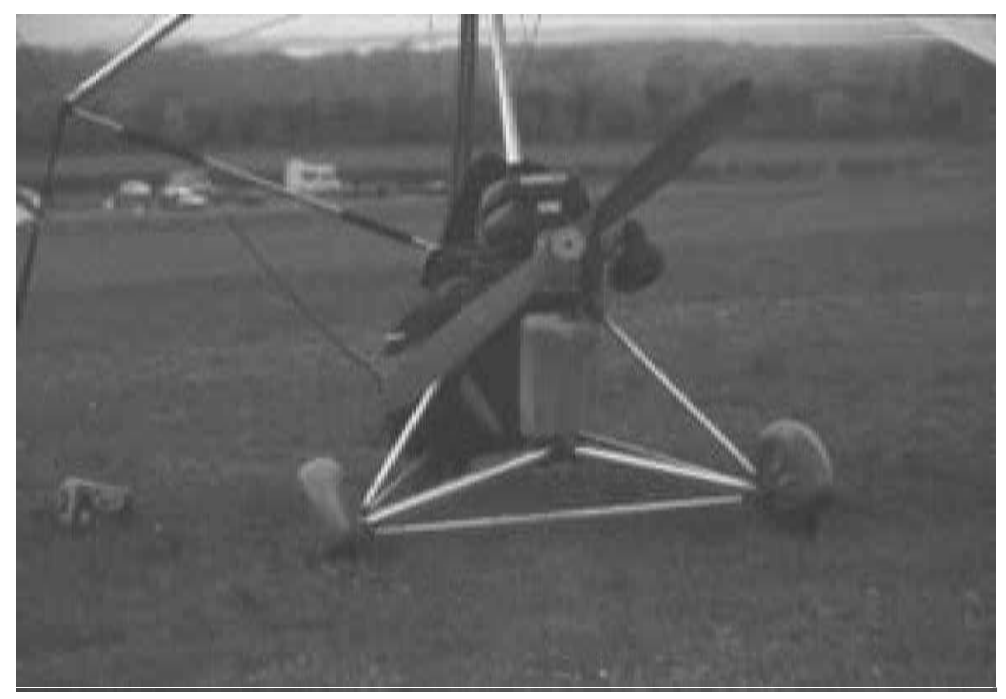

Fig. 8 Rear view of Mainair Gemini trike main undercarriage 
4 Syllabus for the PPL (Microlights), British Microlight Aircraft Association, September 1999.

5 Cosgrove, B. The Microlight Pilots Handbook, 6th edition, 2000.

6 Guide to Airworthiness Procedures, Issue 6, British Microlight Aircraft Association, June 1998.

7 Small light aeroplanes. In British Civil Airworthiness Requirements, Section S, CAP 482, Civil Aviation Publication, 1999.

8 Gratton, G. B. Less weight more fun. Aerospace Int., February 2000, 27(2), 30-32.

9 Microlight Maintenance Schedule MMS1, Technical Information Leaflet 020, British Microlight Aircraft Association, September 1999.

10 Kilkenny, E. Longitudinal static stability of hang-gliders. $\mathrm{PhD}$ thesis, Cranfield University, 1988.

11 Boschi, E. Il delta 'intellegente'. Volare Sport, January 1999, $32-33$.
12 AAIB Bulletin 1/2000, Ref. EW/C99/8/5, Air Accidents Investigation Branch, 2000.

13 Flight Test Schedule BMAA/AW/010b, British Microlight Aircraft Association.

14 Brooks, W. G. Flight testing of flexwings. In Royal Aeronautical Society Forum on Test Flying Airsports Aircraft, Boscombe Down, 27 November 1997. http://www.raes. org.uk/light-av/brooks_p_1.htm.

15 Cook, M. V. The theory of the longitudinal static stability of the hang-glider. Aeronaut. J., October 1994, 98(978), 292-304.

16 Gratton, G. B. and Porteous, T. The creation of a formal test flying system within the British Microlight Aircraft Association and a discussion of the spin testing of microlight aircraft. In European Congress of the Society of Experimental Test Pilots, Regensberg, Bavaria, 2000. http://www.setp.org/microlightaircraft.htm. 
Copyright of Proceedings of the Institution of Mechanical Engineers -- Part G -Journal of Aerospace Engineering is the property of Professional Engineering Publishing and its content may not be copied or emailed to multiple sites or posted to a listserv without the copyright holder's express written permission. However, users may print, download, or email articles for individual use. 